\title{
Orbit Capillary Hemangioma
}

National Cancer Institute

\section{Source}

National Cancer Institute. Orbit Capillary Hemangioma. NCI Thesaurus. Code C4545.

A capillary hemangioma arising from the orbit. 